Resenha da Tese de Doutorado:

\title{
PARA ALÉM DO OU "ISTO" OU "AQUILO": os sentidos da educação das crianças pequenas a partir das lógicas de seus contextos familiares
}

\author{
"Não há roteiros seguros para a iniciação do futuro investigador \\ científico, mas é inegável que a convivência institucionalizada com \\ investigadores experimentados pode ser um caminho \\ interessante"(Azanha, 1992, p. 12)
}

A referida tese, de autoria de Simone Santos de Albuquerque, foi apresentada em 2009 ao Programa de Pós-Graduação em Educação da Faculdade de Educação da Universidade Federal do Rio Grande do Sul, como requisito parcial para obtenção do título de Doutor em Educação. Trabalho que integra um conjunto de investigações da Linha de Pesquisa Estudos sobre Infâncias, orientada pela Profa. Dra. Maria Carmen Silveira Barbosa.

Resultado do processo de pesquisa com seis contextos familiares integrantes de um bairro da periferia urbana do município de Rio Grande/RS, apresentou como foco de análise "compreender como alguns grupos de famílias dos meios populares estruturam suas práticas e lógicas de cuidado/educação das crianças pequenas". Segundo a autora, o trabalho apresenta a importância da análise da prática efetiva dos relacionamentos e interações sociais entre famílias e crianças como possibilidade de reconhecimento de outras lógicas, da criação de novas alternativas, em detrimento da fixação em um “ideal" ou modelo "hegemônico", que é o que tem caracterizado o campo científico na área da Educação Infantil, oportunizando à mesma tornar-se efetivamente uma tarefa pública socialmente compartilhada.

Para o desenvolvimento da pesquisa utilizou como referencial teórico e metodológico a pesquisa qualitativa de cunho etnográfico, realizando uma intensa imersão no bairro, nas casas e nos demais contextos vividos pelas crianças e suas famílias, em suas diversidades e complexidade do cotidiano de cada contexto familiar pesquisado. Foram utilizadas como instrumento de pesquisa a observação participante e entrevistas semiestruturadas. A discussão dos dados produzidos foi realizada a partir do foco analítico dos "contextos familiares". 
Pesquisadora, como oriunda da área da educação, ao assumir a etnografia como procedimento metodológico, coloca-se frente aos desafios provenientes de não ser uma antropóloga de formação e ter que configurar o olhar na perspectiva da antropologia, evidenciando o que é específico daquela comunidade e daqueles contextos familiares.

A relação estabelecida entre as elaborações teórico-metodológicas e a de caráter empírico, resultou no reconhecimento da singularidade e pluralidade de contextos familiares concretos, contextualizados e historicamente situados.

A autora realiza um movimento interdisciplinar e multidisciplinar, utilizando-se de autores das Ciências Sociais e da Educação o que contribuiu para ampliar o universo de análise da pesquisa.Traz no desenvolvimento do mesmo uma crítica à ideia de que a educação das crianças pequenas possui uma única dimensão teórica - a Psicologia, noção esta que vem alterando o panorama e os referenciais da área e contribuindo para a construção e elaboração de outros tratos, tanto no que tange a delimitação das necessidades e características das crianças, como o papel da Educação no seu desenvolvimento integral.

Argumenta quanto a necessidade de rever convicções discorrendo sobre a passagem das certezas de uma fase "sólida" para uma condição reflexiva e problematizadora a cerca do posicionamento teórico que havia desenvolvido durante os anos que se precederam ao curso de doutorado e que se acabam constituindo em certezas científicas e políticas sobre o "que seria melhor" para a educação infantil, em especial para as das camadas populares, principalmente fazendo escolhas para a definição de fundamentos que subsidiassem sua prática profissional.

"[...] o estudo exigiu um despojamento das certezas frente às realidades e uma disposição para ouvir os outros e buscar sentidos e interpretações que eles próprios atribuem às suas vidas. Esta foi uma tarefa um tanto complexa no campo de pesquisa científica, repleto de verdades e certezas nem sempre homogêneas, mas extremamente necessárias para o meio acadêmico, pois se faz urgente compreender outras culturas, outros modos de existência e de educação para entender a heterogeneidade e complexidade em que se encontra a vida contemporânea"(Albuquerque, p.40).

Menciona a contribuição do uso de diferentes linguagens (leitura de histórias reais, de ficção, romance e poesias, música e cinema) como alimento para transformar o vivido em escrita. Para problematizar o sentido desta tese, buscou na poesia de Cecília Meirelles "Ou isto Ou aquilo", o que considerou uma narrativa interessante para a 
reflexão sobre as certezas, sobre a provisoriedade do conhecimento, pela suspensão de certezas únicas e acabadas, sobre o outro e as escolhas que diariamente temos que fazer.

"Ou isto ou aquilo: ou isto ou aquilo... e vivo escolhendo o dia inteiro! Não sei se brinco, não sei se estudo, se saio correndo ou fico tranqüilo. Mas não consegui entender ainda qual é melhor: se é isto ou aquilo".

O sumário, apesar de apresentar uma organização particular e não aleatória da tese, como bem definiu a autora em sua introdução, dá ao leitor a idéia da dimensão da mesma.Escolha esta que fica evidenciada no decorrer de toda a produção, na qual parece ter considerado importante esgotar os dados construídos já que retratavam a trama da vida de pessoas que se tornaram sujeitos históricos da tese.

“[...] através da memória afetiva e reflexiva, busco descrever todos momentos cruciais que demarcaram os caminhos percorridos durante o ano de 2007 nas vivências com os contextos familiares pesquisados[...]"(Albuquerque, 2009, p.19).

Uma escolha a ser pensada para que não se incorra no risco de transformar a pesquisa, ou parte dela, num aglomerado de informações o que poderia afastar o leitor não cativo por mais que o assunto lhe interessasse (Alves-Mazzotti,p.40).

Apesar de demonstrar em seus escritos a preocupação com a reflexão teóricocientífica, Albuquerque traz questões particulares suas para a pesquisa, colocando-se como sujeito da mesma.Menciona que em seu envolvimento com os seis contextos familiares e no cotidiano com suas filhas, foi experimentando outras possibilidades na compreensão do cuidado como uma dimensão da educação. O quanto em algumas vezes se percebia impregnada das lógicas das famílias pesquisadas citando situações que foram reproduzidas com suas filhas. Posicionar-se desta forma pode ter trazido certa fragilidade ao trabalho, uma vez que segundo Bogdan e Biklen (1994, p.113) deve-se ir a campo

"não como alguém que faz uma pequena paragem ao passar, mas como quem vai fazer uma visita; não como uma pessoa que sabe tudo, mas como alguém que quer aprender; não como uma pessoa que quer ser como o sujeito, mas como alguém que procura saber o que é ser como ele" (Bogdan e Biklen, 1994, p. 113-In: Viegas, 2007). 
É certo que uma relação de vínculo e confiança deva ser estabelecida entre o pesquisador e o pesquisado, porém isto não deve vir a influenciar em seu movimento interpretativo. Assim, "o grande desafio é saber trabalhar o envolvimento e a subjetividade, mantendo o necessário distanciamento que requer um trabalho científico. Distanciamento que não é sinônimo de neutralidade, mas que preserva o rigor" (Haguette, 1987, p. 48, itálico da autora-In: Viegas, 2007).

Ao se referir a autoria da tese, Simone afirma que "é preciso tornar clara a dificuldade de "traduzir o vivido", já que a pesquisa foi uma trajetória intensa e coletiva, e as escolhas e escrita da tese, um processo pessoal tendo uma única "autoria", embora compartilhada com muitos" (p. 20).

"Ué, é claro que eu quero que use meu nome, não é a minha história que tu vai contar? Então, este trabalho aí, esta tese é nossa, é a nossa tese" (Deise, participante da pesquisa, p.115, itálico da autora).

Embora o objetivo deste tipo metodológico seja o de tornar audível as vozes de todos os envolvidos e se tenha a clareza de que a pesquisa é feita com o outro e não sobre o outro, é o pesquisador que deve sobretudo assumir a responsabilidade, os resultados da pesquisa.

A questão acima, nos remete a um outro aspecto deste trabalho que fora tratado pela pesquisadora com bastante seriedade - a questão ética. Isto fica evidenciado em várias passagens do mesmo onde demonstra sua preocupação em investigar se as famílias estavam realmente entendendo o sentido da pesquisa, assim como em preservar informações que não gostariam que fossem divulgadas.

No final do processo de pesquisa, mesmo já tendo recolhido as assinaturas do termo de consentimento para utilização de nomes e imagens, além de lembrá-los de que os dados construídos seriam transformados num relatório chamado "tese de doutorado", Simone diz que "não poderia se furtar e nem furtá-los de decidir o que era permitido constar no relatório, mesmo eles já tendo assinado um termo (p. 115). De acordo com Paiva (2005) é preciso preservar o direito de quem colabora com a pesquisa de ser devidamente esclarecido sobre o destino dos dados que estão sendo produzidos.

Para finalizar, coloco em evidência o grande desafio desta produção científica que longe de ser uma pesquisa denunciatória procurou "explicitar a especificidade do modo de vida das famílias pesquisadas, estando atenta não para romantizá-lo, idealizálo ou desqualificá-lo, mas problematizá-lo em relação ao contexto histórico e social 
mais amplo, e sugerir propostas educacionais pensadas para atender às camadas populares" (Albuquerque, p. 88). De abandonar a lógica dominante que muitas vezes caracteriza as famílias como incapazes de cuidar e educar seus filhos devido a confrontação com os padrões e normas dominantes nas instituições de educação ou na sociedade em geral.

“[...] um olhar que não se centrasse na falta, na privação, na negatividade, mas no que é particular, singular e específico naquele contexto"(Albuquerque, p.88).

Para Paiva (2005), expor deficiências sem levar em conta a imprevisibilidade das consequências de uma investigação, sem fazer uma análise dos riscos que os resultados de uma pesquisa podem representar para a imagem dos participantes da pesquisa apenas contribui para desestabilizar o que já está fragilizado, o que é, no mínimo, irresponsável e não solidário.

"Acredito que a maior contribuição desta pesquisa foi entrar para o rol das que questionam a universalidade dos conceitos de infâncias, famílias e educação das crianças pequenas, dando voz aos sujeitos que constituem os contextos familiares e reconhecendo o que sabem e dizem de si, de sua cultura e de suas realidades, lógicas e estratégias na educação de seus filhos."(Albuquerque, p.).

\section{REFERÊNCIAS}

ALBuQuerque, Simone Santos de. Para além do ou "isto" ou "Aquilo": os sentidos da educação das crianças pequenas a partir das lógicas de seus contextos familiares. - Porto Alegre, 2009. 346 f. + Anexo. Tese (Doutorado em Educação) Programa de Pós-Graduação em Educação, Faculdade de Educação, Universidade Federal do Rio Grande do Sul, Porto Alegre, 2009

ALVES-MAZZOTTI, Alda Judith . A "revisão da bibliografia" em teses e dissertações:meus tipos inesquecíveis-o retorno.

AZANHA, José Mário Pires. Uma Idéia de Pesquisa Educacional. São Paulo:Editora da Universidade de São Paulo,1992-(Campi;6) 
FONSECA, Claudia. Quando cada caso não é um caso. Pesquisa etnográfica e educação.Revista Brasileira de Educação. N 10, Jan/Fev/Mar/Abr ,1999 A Bússula do Escrever,

PAIVA, V.L.M.O. Reflexões sobre ética na pesquisa Revista Brasileira de Lingüística Aplicada. Belo Horizonte. Vo. 5, n.1. p.43-61, 2005

VIEGAS, Lygia de Sousa Reflexões sobre a pesquisa etnográfica em Psicologia e Educação Diálogos Possíveis. Janeiro/junho 2007 